\title{
Ruptura de aneurisma renal en la displasia fibromuscular
}

\section{Aneurysm Rupture in Fibromuscular Dysplasia}

\author{
Federica De Gaetano ${ }^{1}$ \\ ${ }^{1}$ Servicio de Diagnóstico por Imágenes del Hospital Italiano de \\ Mendoza, Mendoza, Argentina \\ Rev Argent Radiol 2019;83:68-70.
}

\begin{abstract}
Address for correspondence Federica De Gaetano, Servicio de Diagnóstico por Imágenes del Hospital Italiano de Mendoza, Mendoza, Argentina (e-mail: fededancers@hotmail.com).
\end{abstract}

Estimados Editores,

La displasia fibromuscular (DFM) es una enfermedad de prevalencia desconocida cuyo diagnóstico tarda entre 4 y 9 años desde el comienzo de los síntomas. ${ }^{1}$ Tal demora es ocasionada principalmente por falta de conocimiento de la patología, por no considerarse entre los diagnósticos diferenciales y por no presentar síntomas específicos debido a que las manifestaciones clínicas de la DFM varían de acuerdo a las estructuras vasculares afectadas. Si bien la manifestación clínica más frecuente es la hipertensión arterial (HTA), debería ser un diagnóstico diferencial a tener en cuenta en una amplia variedad de pacientes; no sólo es importante conocer su presentación típica, también deberían reconocerse con facilidad los patrones angiográficos. La DFM es una enfermedad vascular no aterosclerótica, no inflamatoria, sectorial que puede resultar en estenosis y oclusión vascular, aneurismas o disección. Los vasos afectados son los de mediano calibre y en menor medida los de pequeño calibre. ${ }^{2}$ En la DFM existe una relación mujer hombre de 9:1. ${ }^{1}$ La DFM puede presentarse indistintamente en cualquier sexo y a cualquier edad. ${ }^{3}$ La DFM es más frecuentemente diagnosticada en las arterias renales ( $58 \%-75 \%$ ), las carótidas y las vertebrales (25\%$33 \%$ y únicamente en un rango entre $10 \%$ y $30 \%$ afecta otros territorios arteriales. ${ }^{4}$ Aproximadamente el $25 \%$ de los pacientes presentan afectación de más de un territorio arterial. $^{4}$ En un $10 \%$ se pueden ver afectadas arterias viscerales; las más frecuentes son la mesentérica superior, mesentérica inferior y tronco celiaco. ${ }^{1}$

Presentamos el caso de un paciente masculino de 28 años que consultó en guardia por lumbalgia y disuria. El laboratorio reveló aumento de la creatinina y leucopiuria. La ecografía renal resultó normal. Se indicó ciprofloxacina y analgesia. Concurrió nuevamente a la guardia de nuestro centro luego de seis días por presentar dolor en epigastrio irradiado a región lumbar izquierda. Se pidió un nuevo laboratorio, donde persistió el incremento de la creatinina y el sedimento de orina fue normal. El paciente fue internado para evaluación y tratamiento. A las 12 horas de la internación el paciente presentó aumento súbito del dolor en región lumbar izquierda, asociado a caída del hematocrito. Se realizó una tomografía computada multicorte (TC) de abdomen y pelvis, donde se observó una hemorragia retroperitoneal (-Fig. 1). Se descartaron trastornos hematológicos y alteración de la coagulación. Ante esos hallazgos, fue indicada una resonancia magnética (RM) de abdomen y pelvis con gadolinio, que además del sangrado en retroperitoneo puso de manifiesto una alteración en la captación de contraste en el riñón izquierdo y un aneurisma a nivel de la salida del tronco celíaco (-Fig. 2). Se decidió la realización de angiografía renal bilateral y del tronco celiaco. Debido a la insuficiencia renal aguda, el iodo fue diluido y durante el estudio se utilizó escasa cantidad del mismo.

La angiografía confirmó el aneurisma del tronco celiaco (-Fig. 3), y puso de manifiesto múltiples sectores aneurismáticos en ambas arterias renales. Uno de los aneurismas de la arteria renal izquierda presentaba signos de ruptura (-Fig. 3), causante de la hemorragia, así como también vasoespasmo intraparenquimatoso homolateral con consecuente alteración de la fase nefrográfica izquierda, explicando así la insuficiencia renal. Las imágenes angiográficas mostraron el clásico patrón "en collar de perlas" de la DFM. Se descartaron enfermedades autoinmunes y vasculitis apoyando el diagnóstico. El paciente evolucionó favorablemente con tratamiento expectante sin la necesidad de tratamiento endovascular ni quirúrgico debido a que la hemorragia se había autolimitado, con recuperación de la función renal y disminución del dolor, y fue dado de alta a los 21 días del ingreso. Se realizó al mes del alta un control mediante angiografía por resonancia magnética (angioRM), donde se received

August 2, 2017

accepted

May 22, 2018
DOI https://doi.org/

10.1055/s-0038-1661365. ISSN 1852-9992.
Copyright @ 2019, Sociedad Argentina de Radiología. Publicado por Thieme Revinter Publicações Ltda., Rio de Janeiro, Brazil. Todos los derechos reservados.
License terms

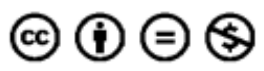




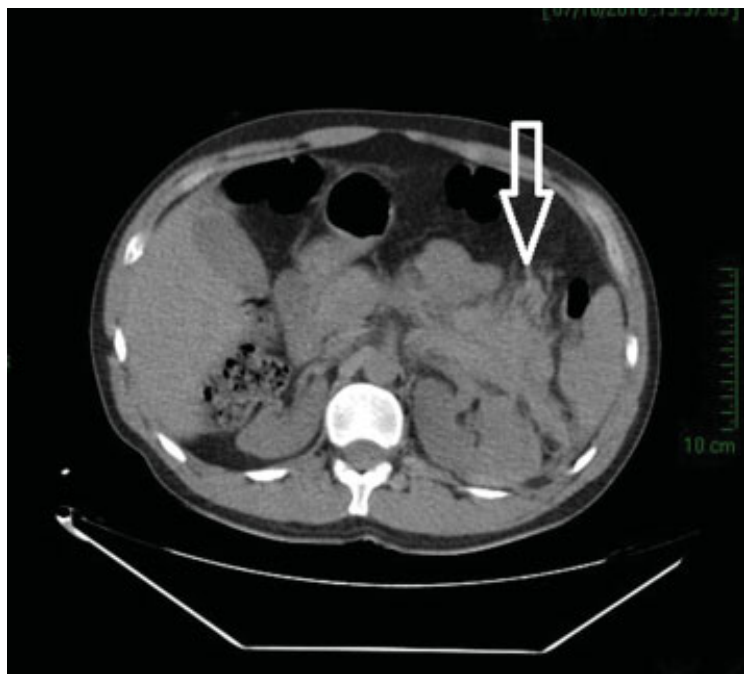

Fig. 1 Corte axial de tomografía computada (TC) sin contraste endovenoso, en donde se observa hemorragia retroperitoneal (Flecha) en el espacio pararrenal anterior.

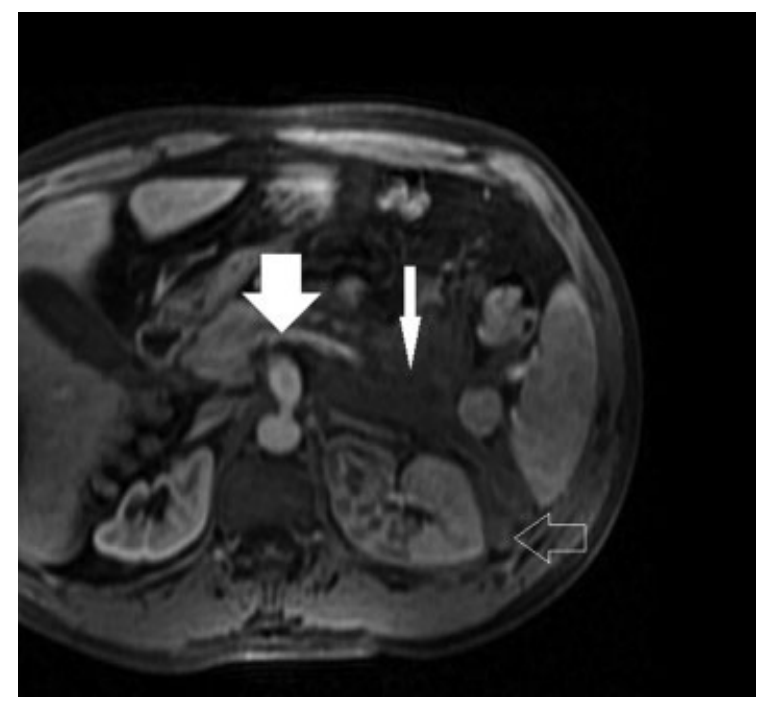

Fig. 2 Resonancia magnética (RM) Axial FatSat T1 con Gadolinio en fase arterial. Flecha sin relleno: alteración de la captación de Gadolinio del riñón izquierdo. Flecha fina: hemorragia retroperitoneal. Flecha gruesa: aneurisma del tronco celíaco.

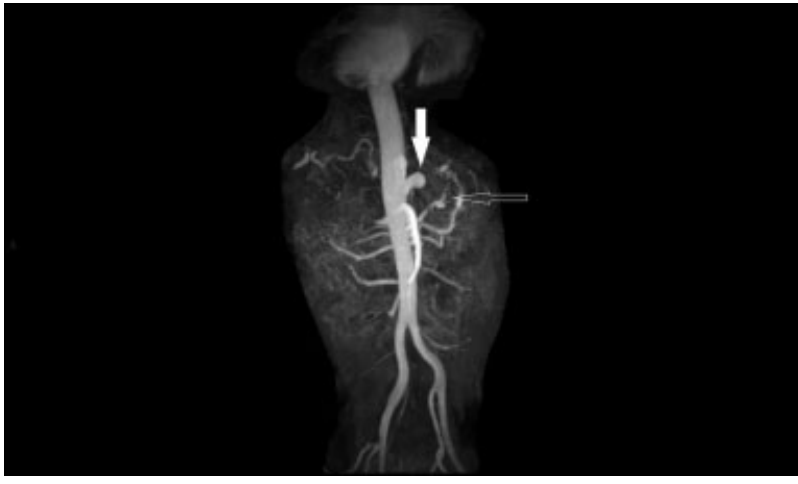

Fig. 4 Angioresonancia magnética abdominal. Flecha sin relleno: signo del "collar de perlas" en la arteria renal izquierda. Flecha con relleno: aneurisma del tronco celíaco.

observó la persistencia de los hallazgos descriptos y la desaparición de la hemorragia retroperitoneal (-Fig. 4).

Clínicamente en la DFM, cuando hay afectación renal, el síntoma más común es la HTA. Debería sospecharse en pacientes menores de 35 años con HTA y resistentes a la medicación. En el $9 \%$ de los casos, la clínica se presenta con epigastralgia o dolor en flanco inclusive sin complicaciones. La insuficiencia renal es muy poco frecuente. Si se afectan las vertebrales o las carótidas la clínica se presenta con mareos transitorios, accidente isquémico transitorio (AIT) o accidente cerebrovascular (ACV). Los aneurismas son más frecuentes en las arterias renales, el tronco celiaco, carótidas y cerebrales. La ruptura aneurismática es muy infrecuente. La disección arterial puede ocurrir en las arterias carótidas, renales y vertebrales. Existen reportes sobre disecciones de arterias viscerales y arterias coronarias. ${ }^{1-4}$ El método de referencia para el diagnóstico es la angiografía, ${ }^{4}$ que presenta tres patrones que se correlacionan con la anatomía patológica: en primer lugar, el patrón de compromiso de la media vascular, donde pueden observarse áreas de estenosis alternadas con sectores de pérdida muscular y consecuente dilatación, produciendo el clásico patrón en "collar de perlas"; en segundo lugar, el patrón de compromiso intimal, que se presenta como bandas concéntricas de constricción focal y por último, el patrón de compromiso adventicial que provoca

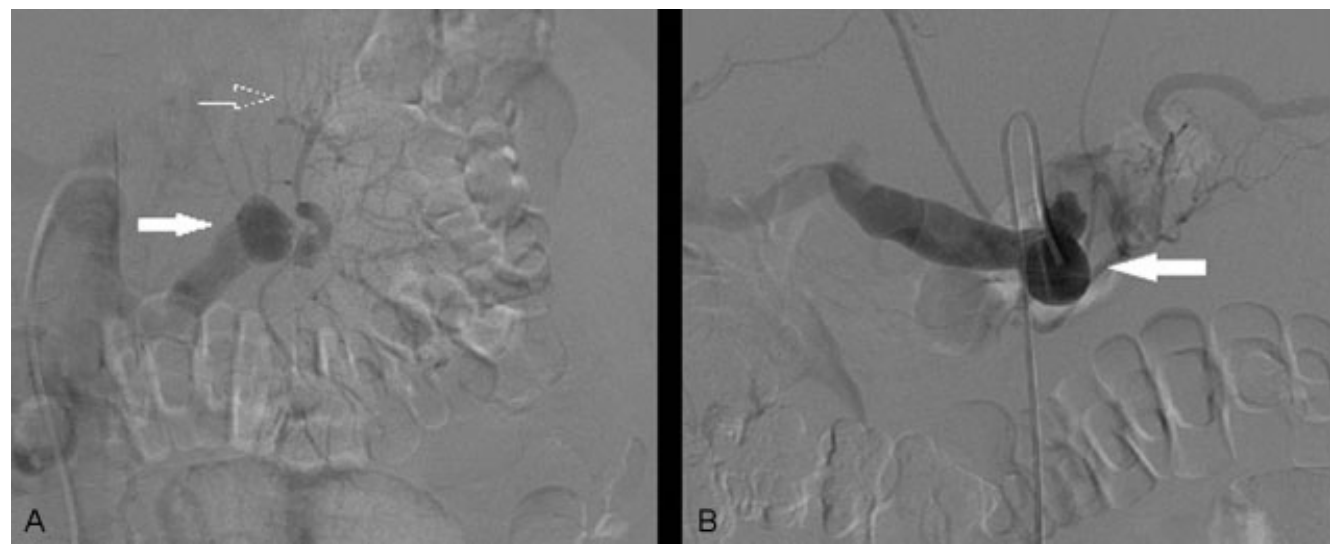

Fig. 3 (A) Angiografía renal izquierda en fase nefrográfica. Flecha con relleno: aneurisma de la arteria renal izquierda con signos de ruptura. Flecha sin relleno: alteración en la fase nefrográfica y vasoconstricción intraparenquimatosa. (B) Angiografía del tronco celíaco. Flecha: aneurisma a nivel del tronco celíaco. 
estenosis tubular. $^{3-5}$ Para el control de la enfermedad son recomendables estudios no invasivos, principalmente la angioRM, al mismo tiempo se puede estudiar la enfermedad carotídea con ecografía Doppler. ${ }^{5}$ Los imagenólogos deben conocer la enfermedad y sus patrones angiográficos para no demorar el diagnóstico. El interés del caso presentado se debe no sólo a su forma de presentación, sino también a la afectación de más de una arteria, incluido el tronco celíaco. El tratamiento de la enfermedad depende de la clínica y del territorio vascular afectado. En los casos de presentación de la enfermedad renal con HTA, controlar los valores tensionales es lo principal. ${ }^{3} \mathrm{La}$ angioplastia transluminal percutánea con balón (PTA), ofrece buenos resultados y remplazó a la cirugía para lograr ese fin. ${ }^{3}$ La PTA también es útil en la enfermedad cerebrovascular. ${ }^{3}$ La colocación de stent en los aneurismas depende del tamaño y la localización. La cirugía es la opción terapéutica más probada en caso de complicaciones. ${ }^{3}$

\section{Confidencialidad de los datos}

Los autores declaran que han seguido los protocolos de su centro de trabajo sobre la publicación de datos de pacientes y que todos los pacientes incluidos en el estudio han recibido información suficiente y han dado su consentimiento informado por escrito para participar en dicho estudio.

\section{Conflicto de Intereses}

Los autores del trabajo declaran no tener ningún conflicto de intereses.

\section{Bibliografía}

1 Olin JW, Gornik HL, Bacharach JM, et al; American Heart Association Council on Peripheral Vascular Disease; American Heart Association Council on Clinical Cardiology; American Heart Association Council on Cardiopulmonary, Critical Care, Perioperative and Resuscitation; American Heart Association Council on Cardiovascular Disease in the Young; American Heart Association Council on Cardiovascular Radiology and Intervention; American Heart Association Council on Epidemiology and Prevention; American Heart Association Council on Functional Genomics and Translational Biology; American Heart Association Council for High Blood Pressure Research; American Heart Association Council on the Kidney in Cardiovascular Disease; American Heart Association Stroke Council. Fibromuscular dysplasia: state of the science and critical unanswered questions: a scientific statement from the American Heart Association. Circulation 2014;129(09): 1048-1078

2 Jahnlova D, Veselka J. Fibromuscular Dysplasia of Renal and Carotid Arteries. Int J Angiol 2015;24(03):241-243

3 Olin JW, Sealove BA. Diagnosis, management, and future developments of fibromuscular dysplasia. J Vasc Surg 2011;53 (03):826-36.e1

4 Van den Driessche A, Van Hul E, Ichiche M, Verpooten GA, Bosmans JL. Fibromuscular dysplasia presenting as a renal infarction: a case report. J Med Case Reports 2010;4:199

5 Varennes L, Tahon F, Kastler A, et al. Fibromuscular dysplasia: what the radiologist should know: a pictorial review. Insights Imaging 2015;6(03):295-307 